\title{
BIM-BASED RISK IDENTIFICATION SYSTEM IN TUNNEL CONSTRUCTION
}

\author{
Limao ZHANG ${ }^{\mathrm{a}, \mathrm{b}}$, Xianguo WU, Lieyun DING ${ }^{\mathrm{a}}$, Miroslaw J. SKIBNIEWSKI ${ }^{\mathrm{b}, \mathrm{c}}$, Yujie $\mathrm{LU}^{\mathrm{d}}$ \\ ${ }^{a}$ School of Civil Engineering \& Mechanics, Huazhong University of Science and Technology, \\ Wuhan, 430074, China \\ ${ }^{b}$ Department of Civil \& Environmental Engineering, University of Maryland, \\ College Park, MD, 20742-3021, USA \\ cInstitute of Theoretical and Applied Informatics, Polish Academy of Sciences, Poland \\ ${ }^{d}$ Department of Building, School of Design \& Environment, National University of Singapore, Singapore
}

Received 25 Apr 2014; accepted 20 Oct 2014

\begin{abstract}
This paper presents an innovative approach of integrating Building Information Modeling (BIM) and expert systems to address deficiencies in traditional safety risk identification process in tunnel construction. A BIM-based Risk Identification Expert System (B-RIES) composed of three main built-in subsystems: BIM extraction, knowledge base management, and risk identification subsystems, is proposed. The engineering parameter information related to risk factors is first extracted from BIM of a specific project where the Industry Foundation Classes (IFC) standard plays a bridge role between the BIM data and tunnel construction safety risks. An integrated knowledge base, consisting of fact base, rule base and case base, is then established to systematize the fragmented explicit and tacit knowledge. Finally, a hybrid inference approach, with case-based reasoning and rule-based reasoning combined, is developed to improve the flexibility and comprehensiveness of the system reasoning capacity. B-RIES is used to overcome low-efficiency in traditional information extraction, reduce the dependence on domain experts, and facilitate knowledge sharing and communication among dispersed clients and domain experts. The identification of a safety hazard regarding the water gushing in one metro station of China is presented in a case study. The results demonstrate the feasibility of B-RIES and its application effectiveness.
\end{abstract}

Keywords: knowledge management, tunnel construction, risk identification, decision analysis, construction safety.

\section{Introduction}

In the past ten years, tunnel construction has presented a powerful momentum for rapid economic development worldwide. However, safety violations occur frequently in tunnel construction due to various risk factors in complex project environments (Zhang et al. 2014). On January 12, 2007, the Pinheiros station on Metro Line Four at San Paulo's Aquarium in Brazil collapsed, causing the death of seven people (Schexnayder 2007). On July 6, 2010, a tunnel collapse took place in Prague, Czech Republic, causing a 15 -meter-wide sunken pit (Thomas 2010). On August 23, 2012, a metro tunnel line leak caused chaos in Warsaw, Poland. Water flooded into the tunnel at the planned Powisle station, causing considerable transportation problems in the already gridlocked city (Waltz 2012). In China, the number of construction accidents in tunnel construction is rising. On November 15, 2008, 21 people were killed as a result of a road cave-in above a metro tunnel under construction in Hangzhou (AFP 2008). At the Shenzhen Metro construction, four accidents resulted in thirteen deaths in 2009 (Elaine 2009). Also, on December 25, 2012, eight people were killed and five others hurt in a fatal tunnel explosion in northern China's Shanxi province (Yu 2012). In general, tunnel construction entails to a highly complicated project with large potential risks, which can bring enormous dangers to public safety.

Above accidents have led to growing public concerns about a prior risk identification and assessment in relation to the tunnel construction safety. Risk identification plays an important role in safety assurance process, aiming to illustrate the potential safety risk/risk factors' contribution to the occurrence of an accident (Zhang et al. 2013). Critical potential risks and risk factors can then be identified in order to assist project engineers in determining critical safety checking points in the construction stage (Zavadskas et al. 2010). Generally, the frequently used methods can be divided into qualitative and quantitative risk analysis tools, including safety check list (SCL), Delphi, Fault Tree Analysis (FTA), Event Tree Analysis (ETA), Hazard and Operability study

Corresponding author: Xianguo $\mathrm{Wu}$

E-mail:wxg0220@126.com 
(HAZOP), and others (Søren et al. 2004). For instance, Šejnoha et al. (2009) conducted a quantitative risk assessment of the tunneling excavation process in a Czech Republic tunnel project using FTA. Hong et al. (2009) employed the ETA technique to provide a quantitative risk evaluation in a tunnel project passed under the Han River in South Korea. Based on these risk analysis tools, in actual construction practice, some domain experts are commonly invited to identify the potential safety risks according to their expertise knowledge accumulated from years of experience, where values of risk related parameters, served as input information, are first obtained by reading the engineering drawing documents. However, three deficiencies mainly exist in the current safety risk identification process: (1) The domain experts' expertise is excessively relied due to a lack of autonomous inference capacity in the current approach. However, domain experts are generally considered as a scarce resource unable to provide universal consultation and real-time guidance because of time constraints; (2) The process of the engineering parameter extraction involves many time-consuming and error-prone activities, especially in reading engineering drawing documents, and therefore, the accuracy and effectiveness of the risk identification results can be significantly affected to some extent; and (3) The expert knowledge is distributed in a scattered and repetitive condition, leading to challenges in knowledge acquisition. This paper aims to present an innovative approach of integrating Building Information Modeling (BIM) and expert systems to address these deficiencies.

BIM is a digital representation of the building process which can facilitate the exchange and interoperability of project information management, and promotes a collaborative process for the Architectural, Engineering, Construction and Facilities Management (AEC/FM) industry. Compared to the conventional two-dimensional (2D) drawings, BIM provides a more realistic and enriched model beneficial to all phases of the building life cycle. BIM offers a geometrically accurate three-dimensional (3D) representation, and the capability to affiliate attributes and data to the components and objects inside a model. The growing implementation of BIM provides potential advantages for safety management in construction design and planning, and further facilitates the integration of construction safety and health practices. BIM is one of the fastest-growing tools that has gained acceptance in the AEC/FM industry worldwide, offering new means and approaches to improve inefficiencies of the current paper-based processes (Ku, Mills 2010). BIM allows various analyses during early design phases to engage clients, and to support facility management and lifecycle costs analyses. BIM can be applied for site hazard prevention and safe project delivery. Hadikusumo and Rowlinson (2002) illustrated that BIM-based design review tools could be utilized to add safety hazards to $3 \mathrm{D}$ geometry objects for hazards identification with the support of database systems. Hardin (2011) noted that the implementation of BIM in construction practice promised to improve the communication and collaboration between participants through higher interoperability of data. Opportunities are identified to promote the safety with the application of BIM by involving partners such as designers, contractors, safety specialists and others.

Safety risk identification plays a core role in construction safety management (Zavadskas et al. 2010), and is very difficult given the complexity and size of the building systems designed. In regard to the tunnel construction, the project safety risks are related to many influential factors, such as structures, construction techniques, geological and hydro-geological conditions. In general, how to calculate and identify the potential safety risk in construction projects remains a challenging problem, since various factors are involved, especially in tunnel construction. Expert Systems (ESs) technique provides a powerful tool for knowledge integration and autonomous inference mechanism (Martín et al. 2012). ESs are designed to solve complex problems by knowledge-based reasoning like a human expert, which can be used to significantly reduce dependence on domain experts. With its strong inference capacities, ESs have been widely applied in knowledge management, automatic fault diagnosis (Wu, Liu 2009), intelligent traffic management (Wen 2010), and other fields in the past two decades. This paper therefore investigates the possibility of merging BIM and ESs to provide an alternative way to conduct the autonomous safety risk identification in tunnel construction, aiming to provide a solution to the aforementioned deficiencies and shortages. In this paper, a BIM-based Risk Identification Expert System (B-RIES) for tunnel construction, mainly consisting of three built-in subsystems: namely BIM extraction subsystem, knowledge base management subsystem, and risk identification subsystem, is developed. B-RIES is used to systematize the fragmented knowledge and facilitate the knowledge sharing and communication among dispersed clients and domain experts. Finally, a typical safety hazard in the Mingdu Station in the Wuhan Metro Line Two of China is presented as a case study. The results demonstrate the feasibility of B-RIES, as well as its application potential.

This paper is organized as follows. In Section 1, an integrated knowledge base is established to systematize the fragmented explicit and tacit knowledge. In Section 2, the system framework of B-RIES and its inference mechanism are proposed. In Section 3, B-RIES is applied for safety risk identification in a tunnel case. The conclusions are drawn in Section 4.

\section{Knowledge-enabled construction safety management}

\subsection{Knowledge resource}

The tunnel construction safety management is considered as a complex system, and various influential variables, including technical, geological and environmental factors, 
are involved. Therefore, the traditional theory-based and analytical methods cannot exactly illustrate the complex interaction among various variables. In this situation, the prior expert knowledge and previous cases can provide a wealth of knowledge resources for safety risk analysis and identification. With the development of tunnel construction practice worldwide, large amounts of scattered knowledge are accumulated, including explicit and tacit knowledge. Sherehiy and Karwowski (2006) noted that both explicit and tacit knowledge was equally important in knowledge base construction, and a balance of both was a major factor in developing an effective knowledgebased system. During the knowledge base construction process, knowledge acquisition plays a very important role, aiming to obtain relevant knowledge from the accumulated knowledge resources. This involves developing new knowledge content and updating old content through socialization, externalization, internalization, and combination. Risk mechanism analysis makes efforts to reveal potential risks/risk factors and their causal relationships, providing a theoretical basis for the knowledge acquisition. To be specific, the risk factors of a specific risk can be acquired from the following two types of knowledge resources:

(1) Explicit knowledge. Explicit knowledge stands for the knowledge resource which can be easily codified and transmitted between individuals in documented and organized forms, such as standard specification, technical manuals and research reports (Sherehiy, Karwowski 2006). The initial risks and their factors can then be achieved by means of knowledge structuralization, expression and explanation. Taking the hazard of "water gushing at foundation pit" as an example, according to the standards, the water gushing hazard refers to an accident that occurs after the loose soil granules have been saturated by the underground water and when hydrodynamic pressure is equal to or greater than submerged unit weight of soil, with the existence of water head difference. Consequently, the terms or keywords concerning the specific risk "water gushing at foundation pit" can be preliminarily achieved, as described in italics.

(2) Tacit knowledge. Tacit knowledge stands for the knowledge resource that is generally developed by an individual through years of working experience. Dialogues and communications among individuals are basic means of knowledge sharing. Therefore, questionnaires, depth interviews and group decision-making methods can be used to reveal the potential risks and their risk factors. Also, numerous scholars built simulation models for the safety analysis, providing valid reference for the relation discovery within various risks (Ding et al. 2011). Accordingly, the parameters of the simulation models can also be added as extra risk factors.

\subsection{Knowledge base construction}

Regarded as a core of an expert system, the knowledge base contains a summary of expert expertise and guidelines, and can be used to implement the intellectualized control system by providing practical supports to the identified problems (Cheung et al. 2004). In this research, an integrated knowledge base is established, consisting of the fact base, rule base and case base.

(1) Fact base. The fact base is used to store values of each risk factor, including the fact code, attribute and credibility factor $(C F(e))$. Different values of a risk related parameter lead to the different credibility degree of the factor being considered as the evidence in accidence occurrence, represented by $C F(e)$. $C F(e)$ takes a value of zero when the evidence is completely unreliable, while $C F(e)$ takes a value of one when the evidence is completely reliable. The more difficult to become the evidence, the smaller the value of its $C F(e)$. Based on the characteristics of safety related factors in tunnel construction, factors are divided into two types, namely certain and uncertain factors. To be specific, the certain factor refers to the risk factor which has discrete values, and therefore its fact $C F(e)$ is a discrete value; the uncertain factor refers to the risk factor which has interval values due to randomness, fuzziness and greyness, and therefore its fact $C F(e)$ can be represented by a sectional function.

(2) Rule base. In tunnel construction, most of the safety-based knowledge is empirical, associated with characteristics, such as diversity, hierarchy and uncertainty. The production rule "IF (premise) THEN (conclusion)" provides a powerful tool for the representation of empirical knowledge and reasoning under uncertainty. The production rule as seen in Eqn (1) is adopted for the rule representation, with the hierarchy and uncertainty of rules taken into account. The causal relationship between the premise $(e)$ and the conclusion $(h)$ is represented by Eqn (2), where $\lambda$ stands for the rule threshold. The rule can be activated if and only if rule evidence $C F(e) \geq \lambda$. Generally, $\lambda$ is defined to range from 0.5 to 1.0 , depending on the importance of the project. The rule credibility $C F(h, e)$ with a scope of $[0,1]$, is related to the credibility degree of the rule, and can be calculated by Eqn (3):

$$
\begin{gathered}
\text { If } e \text { Then } h(C F(h, e), \lambda) ; \\
C F(h)=C F(h, e) \times C F(e) \quad \forall C F(e) \geq \lambda ; \\
C F(h, e)= \begin{cases}\frac{P(h \mid e)-P(h)}{1-P(h)} & P(h \mid e) \geq P(h) \\
-\frac{P(h \mid e)-P(h)}{P(h)} & P(h \mid e)<P(h),\end{cases}
\end{gathered}
$$

where: $P(h)$ stands for the prior probability of the conclusion $h$, and $P(h, e)$ stands for the conditional probability of the conclusion $h$ when the premise $e$ is true. 
(3) Case base. A large amount of accident cases are accumulated in history, which can provides a basis for risk identification in tunnel construction. By matching the characteristics between a specific project and existing cases in the case base, the potential accidents can be detected ahead of time. Compared with rules, we do not need to build explicit rule models (see Eqn (1)) for the case representation. Generally, the case base is an open system, and easy to maintain. It is unnecessary to perform dependency and consistency checking work while adding new cases into the case base (Ng, Luu 2008). To facilitate the efficiency during the case matching process, cases are required to be structured in accordance with the characteristic of domain cases. Accident cases in tunnel construction generally display the characteristic of multi-level and multi-attribute. Accordingly, a case record should consist of various attributes, including Construction project data $\left(C_{1}\right)$, Accident data $\left(C_{2}\right)$, Problems/ Reasons $\left(C_{3}\right)$, Response \& Solutions $\left(C_{4}\right)$, Accident consequence $\left(C_{5}\right)$, and Case application $\left(C_{6}\right)$. Furthermore, each attribute can then be further refined.

\subsection{Knowledge database relations}

Initially, either rules or cases are stored in text forms, which are likely to result in inconvenient retrieval and traversal operations in knowledge-based reasoning. With simple structures, highly independent data and strong description ability, the relational database can be widely employed to store various kinds of knowledge. Therefore, in order to improve data matching and reasoning efficiency, rules and cases can be stored in a relational database, and be retrieved by means of a structured query language.

Both rule and case premises are stored in the fact table, aiming to ensure the consistency of terms in the knowledge base. The rule premise table describes the various states of risk factors. The rule table describes a basic structure of a production rule such as "IF (premise) THEN (conclusion)", representing the relation between the case premise and its conclusion. The case premise table describes the various attributes of case characteristics. The case table describes a structure of a case, showing the relation between case characteristics and their consequences. The case consequence table describes the consequence of the accident case, and provides explanation information for the risk identification results and control measures.

\section{Development of A BIM-based Risk Identification System (B-RIES)}

\subsection{System framework}

In order to facilitate knowledge sharing and communication among dispersed clients and experts during the safety risk identification process, the merging of BIM and ESs provides a full solution for the aforementioned deficiencies and shortages. Thus, a BIM-based Risk Identification Expert System (B-RIES) is developed to systematize the fragmented explicit and tacit knowledge in tunnel construction. A simplified logical framework of B-RIES is

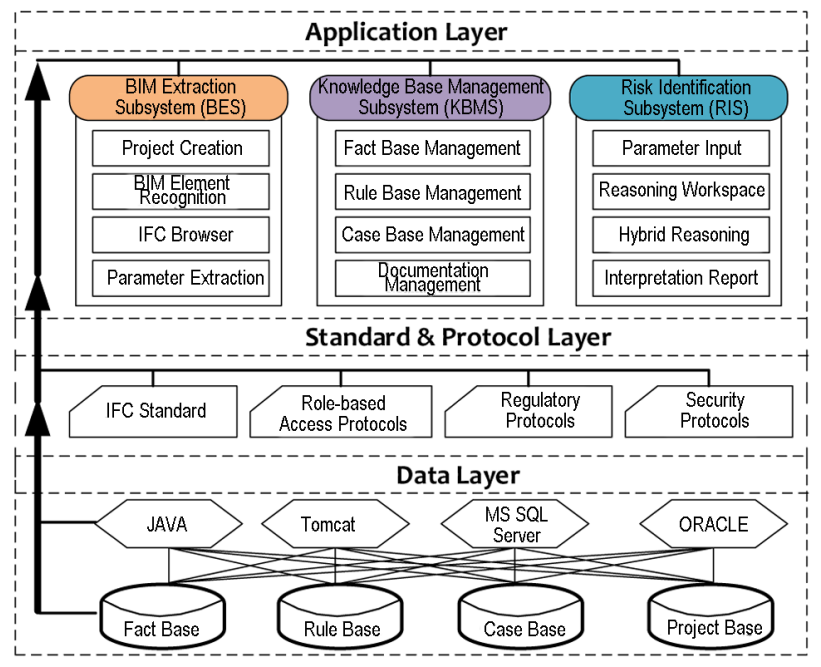

Fig. 1. Simplified logical framework of B-RIES

presented in Figure 1. B-RIES is a distributed multi-layer system consisting of three main layers, namely Data Layer, Standard \& Protocol Layer, and Application Layer, as illustrated as follows.

(1) Data Layer. B-RIES is developed in JAVA programming language and running in the Tomcat container. Mainstream data warehouses consisting of the Microsoft SQL Server and Oracle database system are compatible with the system. In the meantime, four built-in databases, namely Fact Base, Rule Base, Case Base and Project Base, are used to provide data support for the intelligence inference in the overall safety risk identification process.

(2) Standard \& Protocol Layer. This layer provides a unified platform solution for the data communication, processing and interface between the system and external environments using four main types of protocols. To be specific, the Industry Foundation Classes (IFC) standard is employed to extract the information of model components from the input BIM of a specific project. The role-based access protocols aim to set up authorities among dispersed clients, experts and maintainers. The regulatory and security protocols are used to ensure the security of the network environment, resisting threats from external attacks.

(3) Application Layer. This layer provides all functions and services for the system application, mainly consisting of three subsystems: BIM Extraction Subsystem (BES), Knowledge Base Management Subsystem (KBMS), and Risk Identification Subsystem (RIS). B-RIES is a Browser/Server (B/S) system. Particularly, BES aims to extract the engineering parameters of BIM models; KBMS aims to acquire, represent, store and update the risk-based knowledge in tunneling fields; and RIS is used to calculate the risk occurrence probability, and propose control measures in real time. Each subsystem is further composed of o four function modules. 

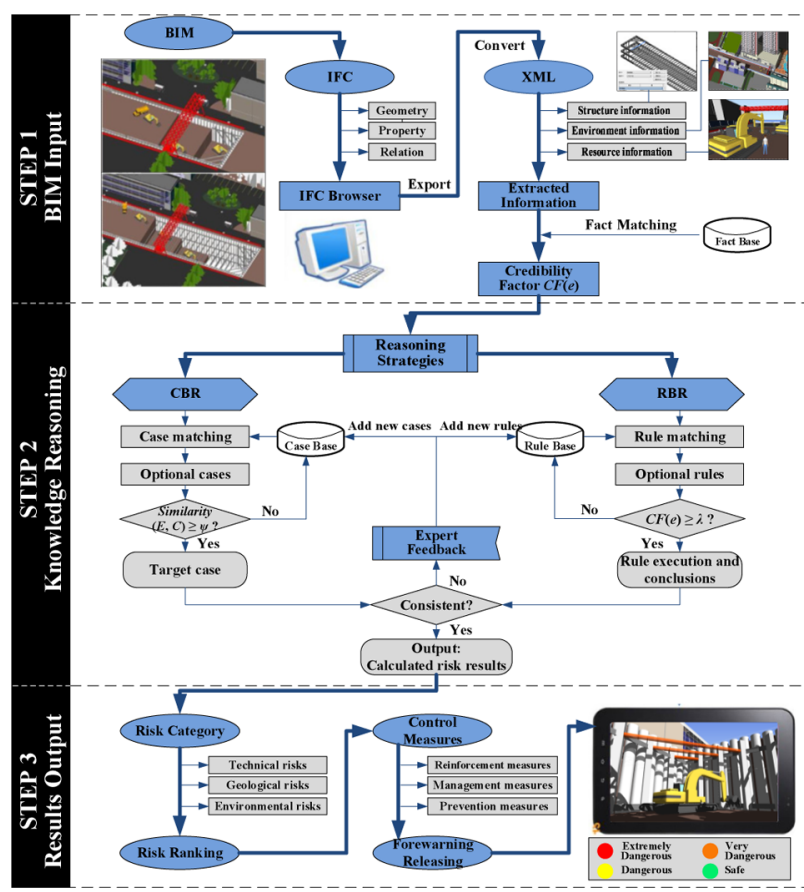

Fig. 2. Safety risk identification process in B-RIES

\subsection{Safety risk identification process}

B-RIES can be used to determine construction safety risks automatically, as well as corresponding control measures. In general, B-RIES will go through the following three steps during the safety risk identification process, as seen in Figure 2.

\section{Step 1: Engineering parameters extraction}

IFC is a schema developed to define an extensible set of consistent data representations of building information for exchange between AEC/FM software applications. All IFC models provide a common general building spatial structure for the layout and accessing of building elements, which can be used to organize all object information into hierarchy of Project-Site-Building-StoreySpace. BIM is considered as an information carrier of engineering parameters which are related to construction safety risks, and the IFC standard plays a bridge role between BIM models and construction safety risks. When BIM models of a specific project are first input into B-RIES, the IFC standard is employed to extract the information of model "components", including geometry, property and relation information related to engineering parameters. Then, the parameter information is exported in the Extensible Mark-up Language (XML) format which is compatible with B-RIES. In the meantime, the recognition results of "components" saved in XML formats are in correspondence with the fact base. When the results are matched with the fact base, the "components" in XML files corresponds with Column "fact name" in the risk fact table. Consequently, the fact base is matched to calculate evidence credibility $C F(e)$ of the risk related engineering parameters. In this way, B-RIES can extract original and objective engineering parameters from BIM models automatically, improving the efficiency of human reading engineering drawings to a large extent.

\section{Step 2: Knowledge reasoning mechanism}

The knowledge reasoning mechanism endows B-RIES with artificial intelligence. Generally, the reasoning in an expert system consists of two approaches, namely rule-based reasoning (RBR) and case-based reasoning (CBR). RBR is known as a reasoning technique with powerful deductive inference capabilities, and can be employed to deal with complicated realistic problems, such as goal programming, scheduling and budgeting (Arch-int, N., Arch-int, S. 2013). However, a RBR system is required to traverse the entire rule base during every reference process, leading to long retrieval time and low efficiency in rule retrieval, especially when the rule base is very large (Lee 2008). In contrast, a CBR system attempts to seek an approximatively similar case using an analogous reasoning technique, and then make a corresponding adjustment for problem solving. The reasoning process in CBR is fast and efficient at the expense of indepth analysis (Kumar et al. 2009). Also, a CBR system has self-learning and self-improvement ability by adding new cases continually as the system grows. However, due to a lack of deductive inference capacity, the CBR system has deficiencies in conformity with strict logical inference, leading to poor interpretability of reasoning results.

In tunnel construction, complex interactions exist among various risk factors, and contribute to the high level of safety violations. This produces a high demand for both rule-based and case-based knowledge during the risk identification process. The integration of RBR and CBR techniques provides a possible solution to the above dilemma. It is also beneficial to improve the flexibility and comprehensiveness of system reasoning capabilities simultaneously. Thus, a hybrid reasoning approach composed of four main sub-steps is proposed in B-RIES as follows:

(1) $C B R$ : Initially, various historical safety-related cases in tunnel construction projects are accumulated and stored in the case base. The objective of CBR is to find out the most similar case as the target case from the case base. At first, the risk related information regarding engineering parameters is obtained from BIM, and then entered into B-RIES as evidence input. Then, some optional cases are selected after being matched with the case base. Finally, the target case is obtained if and only if the similarity is less than the given threshold $\psi$, as seen in Eqn (4). Assuming each case has $n$ attributes to describe the information of engineering parameters, the specific project is denoted by $E=\left(C F\left(e_{1}\right), C F\left(e_{2}\right), \ldots, C F\left(e_{\mathrm{n}}\right)\right)$, and one optional case is denoted by $C=\left(C F\left(c_{1}\right), C F\left(c_{2}\right)\right.$, $\ldots, C F\left(c_{n}\right)$ ). Herein, $C F\left(e_{i}\right)$ (or $C F\left(c_{i}\right)$ ) stands for the credibility factor of $i$ th parameter for the specific project (or the optional case) while being matched with the fact 
base. The Euclidean distance, which is usually used to measure the similarity, is used to calculate the similarity between $E$ and $C$. As seen in Eqn (4), $w_{i}$ stands for the weight of $i$ th parameter based on the expert estimation and construction practice. The threshold $\psi$ is usually given a value ranging from 0 to 0.5 :

$$
\begin{gathered}
\operatorname{Similarity}(E, C)=\sqrt{\sum_{i=1}^{n} w_{i}\left[C F\left(e_{i}\right)-C F\left(c_{i}\right)\right]^{2}} \leq \psi, \\
i=1,2, \ldots, n .
\end{gathered}
$$

(2) RBR: RBR is also incorporated into the knowledge reasoning mechanism, aiming to find out valid rules which can then be executed in the following reasoning process. At first, some optional rules are selected from the rule base by means of rule matching. Next, the valid rule is determined if and only if $C F(e)$ is greater than the given threshold $\lambda$. In general, the premise evidence $e$ is a combination of risk factors $e_{i}(i=1,2, \ldots, n)$, including disjunction, conjunction and weight combinations. Accordingly, $C F(e)$ is calculated by Eqns (5)-(7), respectively. Finally, the valid rule is executed to calculate the credibility degree of the conclusion of the safety related risk using the former Eqn (2):

$$
\begin{gathered}
C F\left(e_{1} \vee e_{2} \vee \ldots \vee e_{n}\right)=\max \left(C F\left(e_{1}\right), C F\left(e_{2}\right),\right. \\
\left.\ldots, C F\left(e_{n}\right)\right) ; \\
C F\left(e_{1} \wedge e_{2} \wedge \ldots \wedge e_{\mathrm{n}}\right)=\min \left(C F\left(e_{1}\right), C F\left(e_{2}\right),\right. \\
\left.\ldots, C F\left(e_{n}\right)\right) ; \\
C F\left(e_{1}\left(w_{1}\right) \wedge e_{2}\left(w_{2}\right) \ldots \wedge e_{\mathrm{n}}\left(w_{\mathrm{n}}\right)\right)= \\
\sum_{i=1}^{n} w_{i} \times C F\left(e_{i}\right) .
\end{gathered}
$$

(3) Expert feedback. As seen in Figure 2, two approaches, CBR and RBR, are included in the knowledge reasoning mechanism. Thus, the result calculated by one approach can be testified by the other. However, when the results are not consistent between these two approaches, domain experts should be involved to solve the problem by adding new rules or cases. Besides that, existing rules stored in the rule base might be modified according to actual situation. At the same time, the verified projects can also be added into the case base as new cases. With a continuous growth of the case base and rule base by means of the self-learning capability in B-RIES, the accuracy and reliability of the system inference mechanism will be continuously improved with development of the system application.

(4) Reasoning strategies. As aforementioned, the RBR approach can reduce the inference efficiency, especially when the scale of the rule base is very large. In order to keep a balance between the high efficiency and accuracy, the reasoning strategies are worked out in accordance with the phase of the system application. To be specific, in the initial stage of the system application, the size of rules (or cases) stored in the rule base (or case base) is relatively small due to a lack of sufficient data. Also, the reliability of the initial rules needs to be verified and improved by comparing with real cases. Thus, RBR and CBR can work in a parallel way in this situation, contributing to expand the scale of the integrated knowledge base by means of expert feedbacks. When the knowledge base grows larger, these two approaches can work in a serial way for the consideration of space-saving in computation. Generally, CBR can be activated ahead of RBR, in order to avoid the low efficiency in rule retrieval. Once the target case is not reached in CBR, the RBR would then be activated.

\section{Step 3: Risk analysis and control}

Based on the calculated results through the knowledge reasoning mechanism, the safety related risk analysis and control measures can then be worked out. As indicated by Ding et al. (2012), the safety risks can be divided into three categories, namely technical, geological and environmental risks, as shown in Figure 2. Particularly, in order to evaluate the degree of the identified safety risk, during the CBR approach, the degree of the identified risk is equal to the risk level in the target case. At the same time, during the RBR approach, the conclusion credibility $C F(h)$, which can be calculated by Eqn (2), is used as an indicator for the risk evaluation. With regard to $C F(h)$ with a range of $[0,1]$, we divide its calculated value into the following four levels, namely "I (Safe, [0, 0.25)), II (Dangerous, [0.25, 0.5)), III (Very Dangerous, $[0.5,0.75))$ and IV (Extremely Dangerous, $[0.75,1.0))$ ". These four levels are defined by four different colors, namely, "Green, Yellow, Orange and Red", respectively. According to the risk identification results, some corresponding safety control measures can then be determined, and early-warning signals can be released in a visualization scenery.

\section{System application}

Wuhan is the largest city in central China with a population of 10.22 million (2013 data) (Statistics 2013). In order to relieve the pressure of urban traffic jam across the Yangtze River, the construction of Wuhan Metro Line Two (WMLT) formally started on August 28, 2006. The $27.7 \mathrm{~km}$ route, with 21 stations and a total investment of nearly US $\$ 3.2$ billion, passed underground on a northwest-southeast alignment between the Hankou and Wuchang districts. The route map of WMLT is shown in Figure 3. Affected by complexities in construction environments, high potential safety risks existed during the drilling progress of WMLT. In this section, B-RIES is applied to identify safety risks at the pre-construction stage of tunnel construction, aiming to provide guidelines for safety assurance at the construction stage. A case in relating to one metro station, Mingdu Station (see the left region in Fig. 3), was presented in this paper for the system application. 


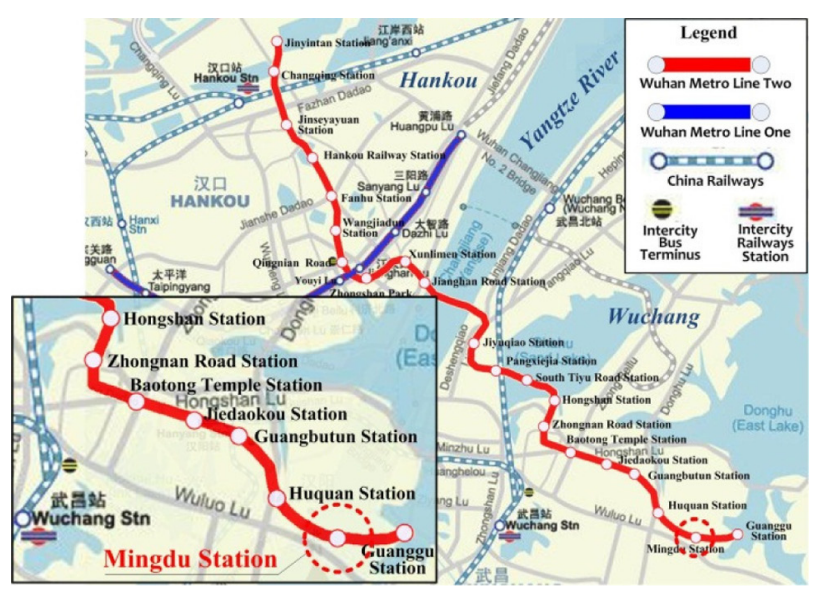

Fig. 3. Map of Wuhan Metro Line Two and Mingdu Station

\subsection{Project profile}

The Mingdu Station is an underground 2-story station. This station was started on November 26, 2008, with an outline length of 241.3 meters, an average width of 18.88 meters, and a total floor area of 11932.1 square meters. A foundation pit with a depth of around 15 meters was excavated using the cut and cover construction method. The aerial view of the BIM model of Mingdu Station is shown in Figure 4. The retaining structure was composed of bored piles and jet grouting piles. Two highrise buildings were adjacent to the deep foundation excavation, specifically, the Baoli Huadu Building was located in the north of the foundation pit, while the Tibetan Middle School was located in the south. The excavation space was limited due to the narrow working site. The working site of the foundation pit excavation of the Mingdu Station is shown in Figure 5.

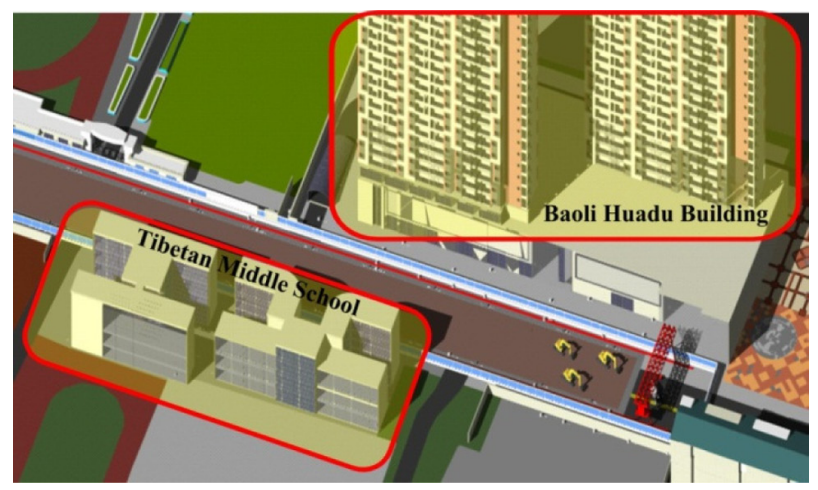

Fig. 4. Aerial view of BIM of Mingdu Station

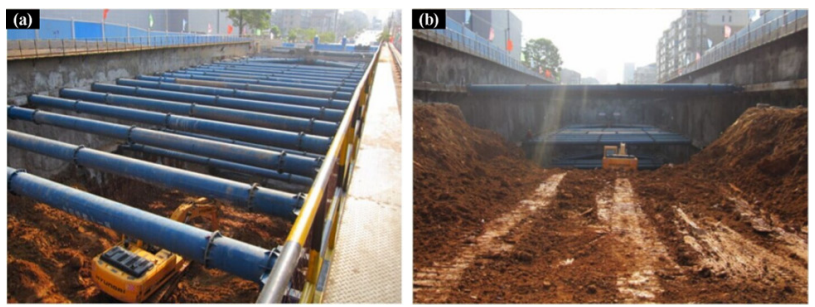

Fig. 5. Working site of the excavation of the Mingdu Station: (a) steel support; and (b) foundation pit
Table 1. Safe risk identification results at the Mingdu Station

\begin{tabular}{|c|c|c|c|c|}
\hline Risk type & $\begin{array}{l}\text { Risk } \\
\text { code }\end{array}$ & $\begin{array}{l}\text { Rule } \\
\text { code }\end{array}$ & $\begin{array}{c}\text { Risk } \\
\text { description }\end{array}$ & $\begin{array}{c}\text { Conclusion } \\
\text { credibility } \\
C F(h) \\
\end{array}$ \\
\hline \multirow{4}{*}{ Technical risk } & C. 101 & $\mathrm{R} 1-26$ & $\begin{array}{l}\text { Water } \\
\text { gushing at } \\
\text { foundation } \\
\text { pit }\end{array}$ & 0.608 \\
\hline & C. 105 & $\mathrm{R} 1-13$ & $\begin{array}{l}\text { Instability } \\
\text { of retaining } \\
\text { structure }\end{array}$ & 0.466 \\
\hline & C. 109 & R1-25 & $\begin{array}{l}\text { Instability } \\
\text { of steel } \\
\text { structure }\end{array}$ & 0.256 \\
\hline & C. 113 & $\mathrm{R} 1-30$ & $\begin{array}{l}\text { Instability } \\
\text { of support } \\
\text { system }\end{array}$ & 0.216 \\
\hline $\begin{array}{l}\text { Geological } \\
\text { risk }\end{array}$ & C. 203 & $\mathrm{R} 2-16$ & $\begin{array}{l}\text { Harmful } \\
\text { geological } \\
\text { conditions } \\
\text { within the } \\
\text { scope of } \\
\text { excavation }\end{array}$ & 0.206 \\
\hline $\begin{array}{l}\text { Environmental } \\
\text { risk }\end{array}$ & C. 309 & R3-02 & $\begin{array}{l}\text { Underground } \\
\text { pipe } \\
\text { cracking and } \\
\text { seepage }\end{array}$ & 0.196 \\
\hline
\end{tabular}

\subsection{Safety risk identification}

In accordance with the safety risk identification process (as mentioned in Section 2) based upon the build-in subsystems of B-RIES (that are BES, KBMS and RIS), the results of safety risk identification at the Mingdu Station were conducted, as shown in Table 1. There were six safety risks that had been identified. To be specific, one risk (that is C.101) was rated in a level of III (Very Dangerous), since $C F(h)$ of this risk fell to a range of [0.50, 0.75]; two risks (that are C.105 and C.109) were rated in a level of II (Dangerous); and three risks (that are C.113, C.203 and C. 309) were rated in a level of I (Safe). In this case, the top risk (that is "water gushing at foundation pit bottom" (C.101)) was taken as an example to illustrate the detailed computation procedures.

(1) Information extraction for engineering parameters. BIM (always in the format of Revit) of the Mingdu Station was first input into B-RIES. By means of the IFC standard, when the BIM model was translated to an IFC model, all the defined objects were composed of the relevant object type and associated geometry, relation and properties. Specifically, some risk related parameters information can then be extracted and recognized from the IFC files. Next, the recognition results were stored in XML format files which can be read in the B-RIES system. Finally, the engineering parameters information saved in the XML files was matched with the fact base to calculate fact credibility $C F(e)$ of the risk related parameters. With regard to the risk of "water gushing at foundation pit bottom", the fact matching results for relevant 
Table 2. Fact matching results for the risk of water gushing

\begin{tabular}{clcc}
\hline Fact code & \multicolumn{1}{c}{ Fact description } & $\begin{array}{c}\text { Fact } \\
\text { attribute }\end{array}$ & $\begin{array}{c}\text { Fact } \\
\text { credibility }\end{array}$ \\
\hline $\begin{array}{c}\text { FID.025 } \\
\left(e_{1}\right)\end{array}$ & $\begin{array}{l}\text { State of retaining pile } \\
\text { embedded in rocks }\end{array}$ & $\begin{array}{c}\text { Not } \\
\text { embedded }\end{array}$ & 1.0 \\
$\begin{array}{c}\text { FID.036 } \\
\left(e_{2}\right)\end{array}$ & $\begin{array}{l}\text { Water head difference } \\
\text { of foundation pit }\end{array}$ & $3 \mathrm{~m}$ & 0.6 \\
$\begin{array}{c}\text { FID.100 } \\
\left(e_{3}\right)\end{array}$ & Geological condition & Silt & 0.8 \\
$\begin{array}{c}\text { FID.101 } \\
\left(e_{4}\right)\end{array}$ & $\begin{array}{l}\text { Reinforcement state } \\
\text { of foundation pit }\end{array}$ & $\begin{array}{c}\text { Not } \\
\text { bottom }\end{array}$ & 1.0 \\
$\begin{array}{c}\text { FID.126 } \\
\left(e_{5}\right)\end{array}$ & $\begin{array}{l}\text { Embedded length } \\
\text { ratio of bored pile }\end{array}$ & 0.8 & 0.4 \\
$\begin{array}{c}\text { FID.128 } \\
\left(e_{6}\right)\end{array}$ & $\begin{array}{l}\text { Bed thickness of } \\
\text { foundation pit bottom }\end{array}$ & 510 mm & 0.6 \\
\hline
\end{tabular}

risk factors are presented in Table 2. To be specific, some risk factors were easy to be identified directly during the BIM extraction process, such as the water head difference of foundation pit $\left(e_{2}\right)$, the embedded length ratio of bored pile $\left(e_{4}\right)$ and the bed thickness of foundation pit bottom $\left(e_{6}\right)$. However, the information in relating to the other risk factors can be extracted through certain intermediaries. Taking the state of retaining pile embedded in rocks $\left(e_{1}\right)$ as an example, the strata at the bottom of the retaining pile acted as an intermediary, and its properties were first extracted. If the bottom strata was identified to be the rock, it meant that the retaining pile was embedded in rocks, and then the fact credibility of $C F\left(e_{1}\right)$ should be recognized to be 1.0 consequently. Otherwise, the fact attribute should be termed "Not embedded", and then the fact credibility of $C F\left(e_{1}\right)$ should be recognized to be 0 .

(2) CBR approach. According to the extracted risk related parameter information (see Table 2), the case base was matched until the target case was figured out during the case retrieval. Eqn (4) was used to compare the similarity between the specific case and the potential target case. With regard to the risk of water gushing, the target case was identified to be the Guicheng Station, since the similarity between the specific project and the target was calculated to be 0.192 (that is less than the given threshold $\psi=0.3$ ). The case matching result is presented in Figure 6. Actually, the Guicheng Station was one station of the Guanzhou metro systems in Guanzhou, China. On July 31,2008 , great quantities of water swarmed into the Guicheng Station under construction, resulting in serious

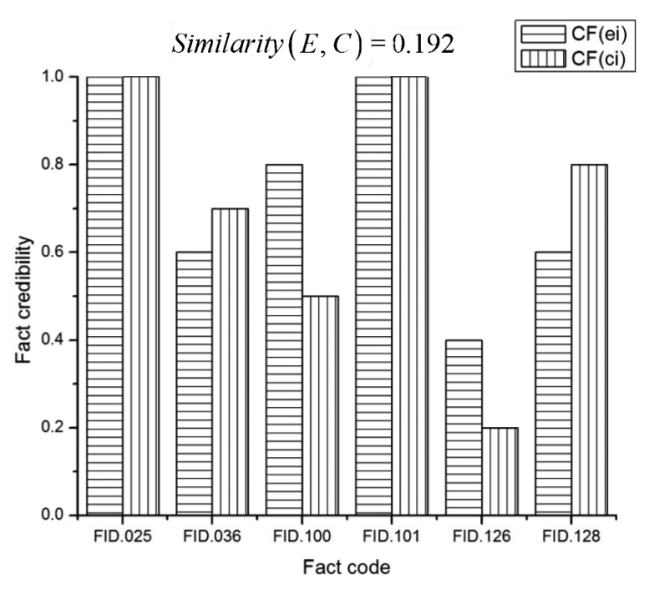

Fig. 6. Case matching result for the risk of water gushing

ground subsidence and construction delay. The hazard level of this accident was evaluated to be a level of III during the accident investigation. Based upon the causal relationship and control process of that accident in the target case, the project engineers can have a deep understanding of the potential safety risk at the Mingdu Station. Also, the risk level and some relevant safety control measures can be conducted.

(3) RBR approach. Based on the aforementioned procedures in the RBR approach, the rule base was first matched to select suitable rules. It is known that worksite type was "station" (represented by No.10) while the construction method was "cut and cover" (represented by No. 1110). Table 3 listed some optional rules for the risk of water gushing. Using Eqns (5)-(7), CF (e) of R1-11 and R1-14 was less than the threshold $\lambda$, therefore both were discarded. Next, $C F(e)$ of R1-26 was calculated to be 0.76 as follows:

$$
\begin{gathered}
C F(e)=1.0 \times 0.2+0.6 \times 0.2+0.8 \times 0.25+ \\
01.0 \times 0.3+0.4 \times 0.1+0.6 \times 0.1=0.76 .
\end{gathered}
$$

Thus, $C F(e)>\lambda=0.5$, indicating that the rule R1-26 was valid. Accordingly, Eqn (2) was used to calculate the conclusion credibility as follows:

$$
C F(h)=C F(h, e) \times C F(e)=0.76 \times 0.8=0.608 .
$$

As a result, the risk of "water gushing at foundation pit

\begin{tabular}{|c|c|c|c|c|c|}
\hline $\begin{array}{l}\text { Rule } \\
\text { code }\end{array}$ & Rule premise description & $\begin{array}{l}\text { Worksite } \\
\text { type }\end{array}$ & $\begin{array}{c}\text { Construction } \\
\text { method }\end{array}$ & $\begin{array}{c}\text { Rule } \\
\text { credibility }\end{array}$ & $\begin{array}{c}\text { Threshold } \\
\lambda\end{array}$ \\
\hline $\mathrm{R} 1-11$ & $\neg$ FID.025 $\vee \neg F I D .036 \vee \neg F I D .101$ & 10 & 1110 & 0.5 & 0.9 \\
\hline $\mathrm{R} 1-14$ & FID. $025 \wedge$ FID. $036 \wedge$ FID. $100 \wedge$ FID. $101 \wedge$ FID. $126 \wedge$ FID. 128 & 10 & 1110 & 1 & 0.8 \\
\hline $\mathrm{R} 1-26$ & $\begin{array}{l}\text { FID. } 025(0.2) \wedge \text { FID. } 036(0.2) \wedge \text { FID. } 100(0.3) \wedge \text { FID. } 101(0.1) \wedge \\
\text { FID. } 126(0.1) \wedge \text { FID.128(0.1) }\end{array}$ & 10 & 1110 & 0.8 & 0.5 \\
\hline
\end{tabular}
bottom" was rated at a risk level of III (Very dangerous).

Table 3. Rule matching result for the risk of water gushing 


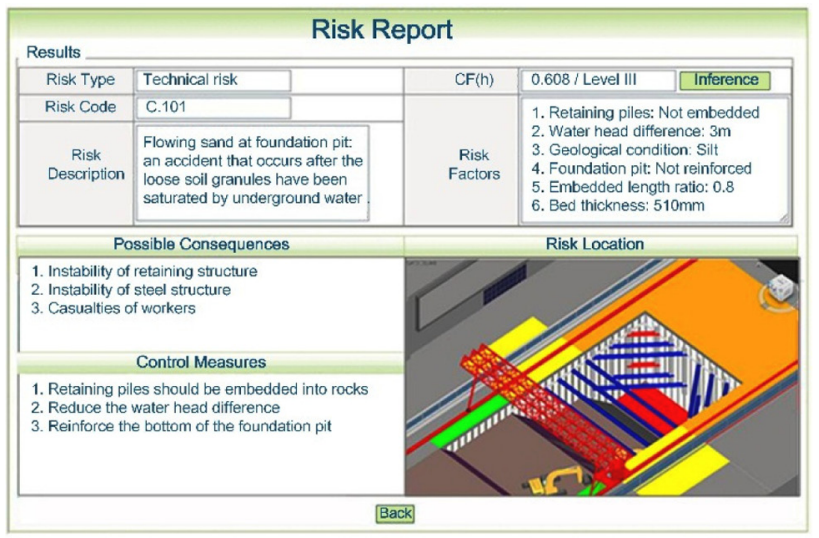

Fig. 7. Report of the water gushing risk at the Mingdu Station

(4) Risk identification and report. The results can be testified when RBR and CBR worked in a parallel way. In this case, the results were consistent between these two approaches. The safety related risk analysis and control measures can then be determined, including the risk type, description, location, possible consequences, risk level and control measures. The report of the risk of "water gushing at foundation pit bottom" at the Mingdu Station is shown in Figure 7.

\subsection{Implementing effects}

According to the risk identification results from B-RIES, the contractor strictly implemented the work of dewatering on the working site during the construction stage, controlled the water head difference between the inside and outside of the foundation pit and reinforced the foundation pit bottom so as to reduce risk limit. Also, emergency supplies, equipment and personnel were prepared in advance to cope with the risk events which were very likely to occur.

On September 14, 2009, a risk event of water gushing was witnessed at the Mingdu Station, as shown in Figure 8a. The volume of the gushing water was small, and its impacts on the safety of nearby retaining piles and adjacent buildings were limited, since some prevention measures were adopted ahead of time. Subsequently, a precipitation well was built up at a location of the water gushing, and continued to be effective until the main structural work of the Mingdu Station was completed, as shown in Figure 8b. As a matter of fact, with effective safety control measures implemented, the construction of the Mingdu Sation went smoothly, and no accidents occurred during the excavation construction process. Finally, the main underground structural work was completed on schedule on August 9, 2010.

\section{Conclusions}

This paper describes an innovative approach of integrating BIM and ESs to address deficiencies in traditional safety risk identification process in tunnel construction. Composed of three main built-in subsystems, namely
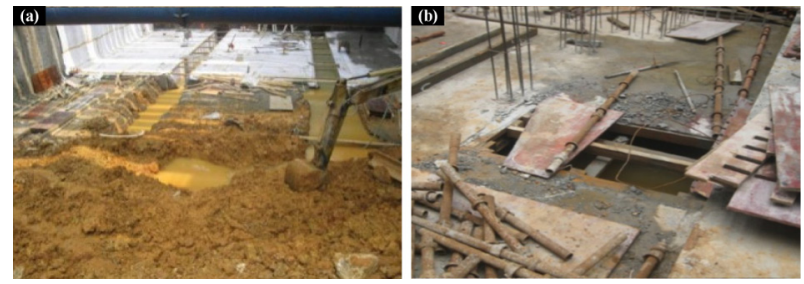

Fig. 8. Risk event of water gushing at the Mingdu Station: (a) location of water gushing; and (b) a precipitation well

BIM extraction, knowledge base management and risk identification subsystems, B-RIES is developed to provide real-time support for decision making in the tunnel risk management through the BIM system. In general, the computerized construction safety risk identification mainly consists of three steps: (1) Engineering parameter information related to risk factors should be first acquired from BIM models of a specific project, where the IFC standard acts as an intermediary between the BIM data and risk related information; (2) An integrated knowledge base, composed of fact, rule and case bases, is built up to systematize the fragmented explicit and tacit knowledge for knowledge sharing and communication among dispersed clients and domain experts; and (3) A hybrid reasoning approach with CBR and RBR combined can be used to improve the flexibility and comprehensiveness of the system reasoning capacity. Finally, the results of safety related risks and their occurrence probability and control measures can be achieved in real time. B-RIES can be used by practitioners in the industry as a decision support tool by providing guidelines on risk assessment and management in tunnel construction, and thus increase the likelihood of a successful project in a complex environment.

Due to the efforts of all participants and the implementation of the developed system B-RIES, no accidents occurred during the construction of the WMLT. Thus, this system has proven to be an attractive potential replacement for the conventional expert-based approach in safety risk identification process. In the past, only experienced engineers/experts were able to identify potential safety risks, and aware of the unexpected dangerous situations and accidents. One benefit of the developed system in this research is that the dependence on domain experts can be reduced, and the knowledge sharing and communication in construction management among dispersed clients and domain experts can be facilitated. Furthermore, the lowefficiency in traditional information extraction from 2D drawing documents can be improved, regarding the BIM techniques are involved and implemented in the developed system.

The developed B-RIES also has some limitations. A large number of rules serving for safety risk identification were obtained from domain experts for the system development. Numerous domain experts participated in the collection, editing, reorganizing work of the safety related knowledge resources, making an essential contribution to securing a qualified rule base for the development of 
B-RIES. However, this process was laborious and susceptible to human error. Our subsequent research goal will focus on automatic knowledge acquisition regarding different knowledge resources, as well as adopting a Rough Set (RS) approach to develop a real-time system for data processing and decision rule generation.

\section{Acknowledgements}

The National Natural Science Foundation of China (Grant No. 51378235), Postdoctoral Science Foundation of China (Grant No. 2015M570645), Hubei Provincial Natural Science Fund (Grant No. 2014CFA117), Wuhan City Construction Committee Support Project (Grant No. 201334) and Henan Provincial Natural Science Fund (Grant No. 132102210262) are acknowledged for their financial support of this research.

\section{References}

AFP. 2008. 21 dead in China subway accident: state media [online], [cited 4 May 2014]. Available from Internet:

http://www.emirates247.com/eb247/news/asia/21-dead-in-china-subway-accident-state-media-2008-11-19-1.227244.

Arch-int, N.; Arch-int, S. 2013. Semantic ontology mapping for interoperability of learning resource systems using a rulebased reasoning approach, Expert Systems with Applications 40(18): 7428-7443.

http://dx.doi.org/10.1016/j.eswa.2013.07.027

Cheung, S. O.; Cheung, K. K. W.; Suen, H. C. H. 2004. CSHM: web-based safety and health monitoring system for construction management, Journal of Safety Research 35(2): 159-170. http://dx.doi.org/10.1016/j.jsr.2003.11.006

Ding, L. Y.; Wu, X. G.; Li, H.; Luo, H. B.; Zhou, Y. 2011. Study on safety control for Wuhan metro construction in complex environments, International Journal of Project Management 29(7): 797-807. http://dx.doi.org/10.1016/j.ijproman.2011.04.006

Ding, L.Y.; Yu, H. L.; Li, H.; Zhou, C.; Wu, X. G.; Yu, M. H. 2012. Safety risk identification system for metro construction on the basis of construction drawings, Automation in Construction 27: 120-137. http://dx.doi.org/10.1016/j.autcon.2012.05.010

Elaine. 2009. Shenzhen Metro No. 3 Line collapsed again. November 13, 2009 [online], [cited 4 May 2014]. Available from Internet: http://www.szcpost.com/2009/11/shenzhenmetro-no-3-line-collapsed-again.html $\backslash$

Hadikusumo, B. H. W.; Rowlinson, S. 2002. Integration of virtually real construction model and design-for-safety-process database, Automation in Construction 11(5): 501509. http://dx.doi.org/10.1016/S0926-5805(01)00061-9

Hardin, B. 2011. BIM and construction management: proven tools, methods, and workflows. Wiley Int. 364 p.

Hong, E.-S.; Lee, I.-M.; Shin, H.-S.; Nam, S.-W.; Kong, J.-S. 2009. Quantitative risk evaluation based on event tree analysis technique: application to the design of shield TBM, Tunnelling and Underground Space Technology 24(3): 269-277. http://dx.doi.org/10.1016/j.tust.2008.09.004

$\mathrm{Ku}, \mathrm{K}$.; Mills, T. 2010. Research needs for building information modeling for construction safety, in International Proceedings of Associated Schools of Construction 45 Annual Conference, 2010, Boston, MA, USA. 8 p.

Kumar, K. A.; Singh, Y.; Sanyal, S. 2009. Hybrid approach using case-based reasoning and rule-based reasoning for domain independent clinical decision support in ICU, Expert Systems with Applications 36(1): 65-71.

http://dx.doi.org/10.1016/j.eswa.2007.09.054
Lee, G. H. 2008. Rule-based and case-based reasoning approach for internal audit of bank, Knowledge-Based Systems 21(2): 140-147.

http://dx.doi.org/10.1016/j.knosys.2007.04.001

Martín, A.; León, C.; Luque, J.; Monedero, I. 2012. A framework for development of integrated intelligent knowledge for management of telecommunication networks, Expert Systems with Applications 39(10): 9264-9274. http://dx.doi.org/10.1016/j.eswa.2012.02.078

Ng, S.-t. T.; Luu, C. D. T. 2008. Modeling subcontractor registration decisions through case-based reasoning approach, Automation in Construction 17(7): 873-881. http://dx.doi.org/10.1016/j.autcon.2008.02.015

Søren, D. E.; Tengborg, P.; Kampmann, J.; Holst Veicherts, T. 2004. Guidelines for tunnelling risk management: international tunnelling association, working group No. 2, Tunnelling and Underground Space Technology 19(3): 217237. http://dx.doi.org/10.1016/j.tust.2004.01.001

Schexnayder, C. J. 2007. Sao Paulo officials launch probe after deadly collapse. January 12, 2007 [online], [cited 4 May 2014]. Available from Internet: http://enr.construction. com/news/transportation/archives/070129a.asp

Šejnoha, J.; Jarušková, D.; Špačková, O.; Novotná, E. 2009. Risk quantification for tunnel excavation process, in Proc. of World Academy of Science, Engineering and Technology, 101-109.

Sherehiy, B.; Karwowski, W. 2006. Knowledge management for occupational safety, health, and ergonomics, Human Factors and Ergonomics in Manufacturing 16(3): 309-319. http://dx.doi.org/10.1002/hfm.20054

Statistics. 2013. National economy and society developed statistical bullet of Wuhan, China in 2013 [online], [cited 4 May 2014]. Available from Internet:

http://www.whzg.org.cn/tzgg/20555.jhtml

Thomas, T. 2010. Breaking news - Prague ring road tunnel collapse. July 6, 2010 [online], [cited 4 May 2014]. Available from Internet: http://tunnellingjournal.com/news/breakingnews-prague-ring-road-tunnel-collapse/

Waltz, G. 2012. Metro line leak causes chaos in Warsaw. August 23, 2012 [online], [cited 4 May 2014]. Available from Internet: http://redaktorext.polskieradio.pl/1/9/ Artykul/110064,Metro-line-leak-causes-chaos-in-Warsaw- $\backslash$

Wen, W. 2010. An intelligent traffic management expert system with RFID technology, Expert Systems with Applications 37(4): 3024-3035.

http://dx.doi.org/10.1016/j.eswa.2009.09.030

Wu, J.-D.; Liu, C.-H. 2009. An expert system for fault diagnosis in internal combustion engines using wavelet packet transform and neural network, Expert Systems with Applications 36(3): 4278-4286.

http://dx.doi.org/10.1016/j.eswa.2008.03.008

Yu, F. 2012. Fatal N China explosion covered up: Authorities [online], December 25, 2012 [cited 4 May 2014]. Available from Internet: http://english.cri.cn/6909/2013/01/03/2941s741834.htm\

Zavadskas, E. K.; Turskis, Z.; Tamošaitiene, J. 2010. Risk assessment of construction projects, Journal of Civil Engineering and Management 16(1): 33-46.

http://dx.doi.org/10.3846/jcem.2010.03

Zhang, L.; Skibniewski, M. J.; Wu, X.; Chen, Y.; Deng, Q. 2014. A probabilistic approach for safety risk analysis in metro construction, Safety Science 63: 8-17. http://dx.doi.org/10.1016/j.ssci.2013.10.016

Zhang, L.; Wu, X.; Ding, L.; Skibniewski, M. J. 2013. A novel model for risk assessment of adjacent buildings in tunneling environments, Building and Environment 65: 185194. http://dx.doi.org/10.1016/j.buildenv.2013.04.008 
Limao ZHANG. He is a doctor at Huazhong University of Science and Technology, and is a visiting scholar of Project Management Centre at University of Maryland, College Park. He obtained his Bachelor in Project Management at Huazhong University of Science and Technology in 2009, and immediately entered a Master-to-PhD combined program in Construction Engineering \& Management from School of Civil Engineering \& Mechanics at the same university. He passed his doctoral defence on October 10, 2014. His research interests are construction safety management and decision support systems.

Xianguo WU. Dr, is a Professor in Project Management in the School of Civil Engineering \& Mechanics, at the Institute of Huazhong University of Science and Technology, China. Prof. Wu received a PhD degree in Structural Engineering at Huazhong University of Science and Technology. Her research interests are construction engineering and management.

Lieyun DING. Dr, is a Professor in Project Management in the School of Civil Engineering \& Mechanics, at the Institute of Huazhong University of Science and Technology. Prof. Ding received a PhD degree in Project Management at Tongji University. His research interests are construction management and web-based systems.

Miroslaw J. SKIBNIEWSKI. Dr, is a Professor of Project Management in the A. James Clark School of Engineering at the University of Maryland, College Park. Prior to his current appointment, he served for 20 years as a faculty member and administrator at Purdue University in West Lafayette, Indiana. He received his M.Eng. Degree from Warsaw University of Technology, and his M.S. and Ph.D. degrees from Carnegie-Mellon University. Prof. Skibniewski is also alum of the Harvard University Graduate School of Education Management Development Program. Prior to his academic career he worked as an engineering professional with the 130+ years-old Pittsburgh Testing Laboratory, a nationwide construction engineering consulting firm in Pennsylvania later renamed to Professional Service Industries, Inc. where he led structural and construction safety investigations, design quality reviews, construction claims reviews, value engineering, and forensic engineering projects.

Yujie LU. Dr, is an Assistant Professor of Department of Building, School of Design \& Environment, National University of Singapore, Singapore. Prior to his current appointment, he obtained his Bachelor in Civil Engineering (structure) from Tongji University in 2006, immediately entered a Master-to-PhD combined program in Construction Engineering \& Management from School of Economics \& Management at the same university, and completed his doctoral degree in March 2012. His research interests are sustainable infrastructure and built environment. 